Supporting Information for:

\title{
Graphene-based Recyclable Photo-Absorbers for High-Efficiency Seawater Desalination
}

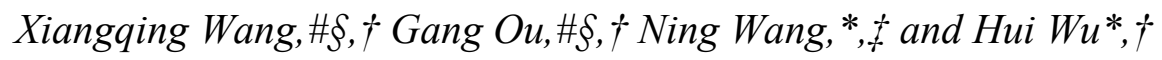

$\dagger$ State Key Laboratory of New Ceramics and Fine Processing, School of Materials Science and Engineering, Tsinghua University, Beijing, 100084, China

* State Key Laboratory of Electronic Thin Film and Integrated Devices, University of Electronic Science and Technology of China, Chengdu 610054, P. R. China

Email: huiwu@tsinghua.edu.cn and wangninguestc@gmail.com 

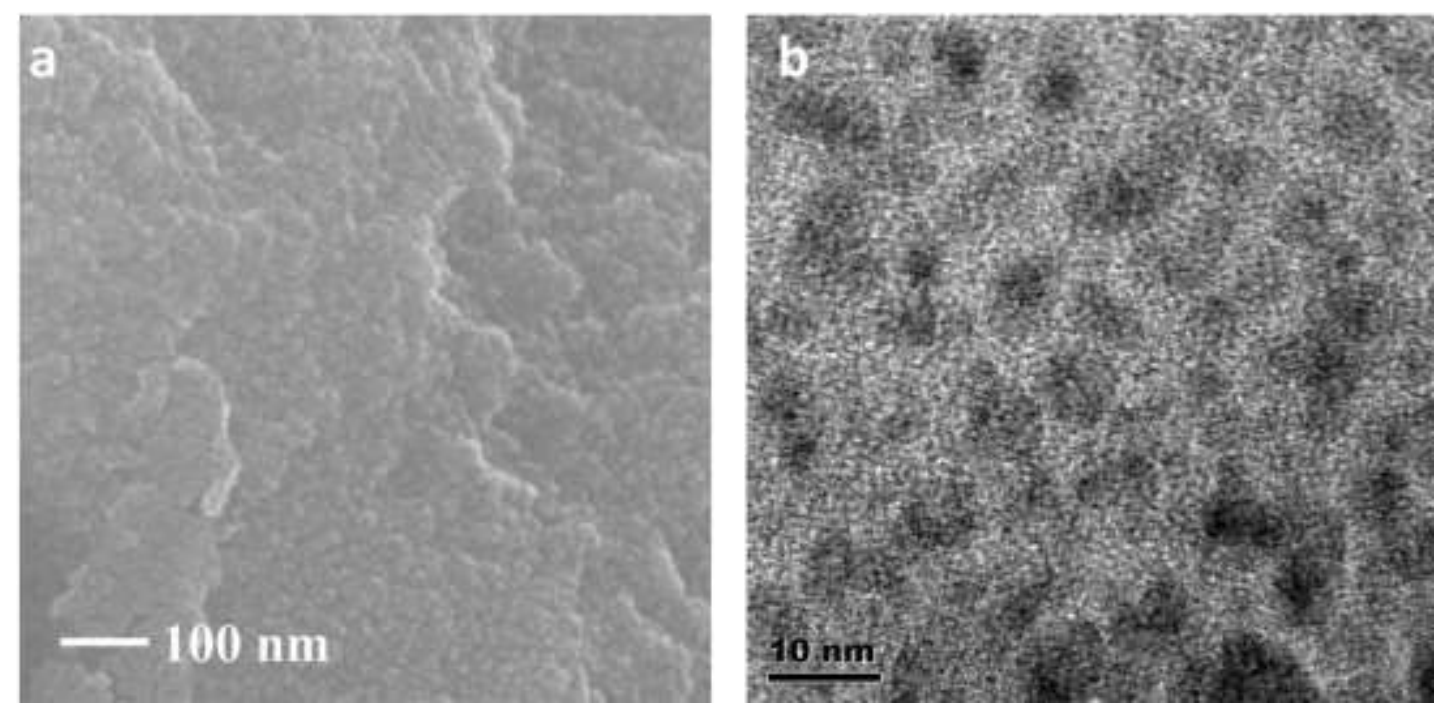

Figure S1. SEM and TEM image of $\mathrm{Fe}_{3} \mathrm{O}_{4}$ MNPs. The TEM image suggests an average particle size below $10 \mathrm{~nm}$ of $\mathrm{Fe}_{3} \mathrm{O}_{4}$ MNPs.

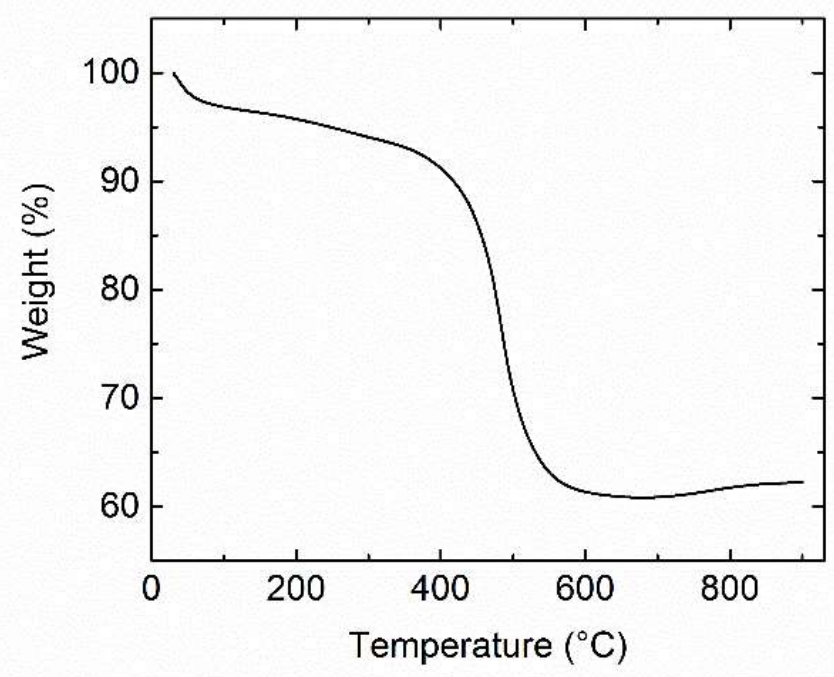

Figure S2. Thermogravimetric curve of $\mathrm{rGO}-\mathrm{Fe}_{3} \mathrm{O}_{4}$. The $\mathrm{rGO}-\mathrm{Fe}_{3} \mathrm{O}_{4}$ powders were completely oxidized to $\mathrm{Fe}_{2} \mathrm{O}_{3}$. 


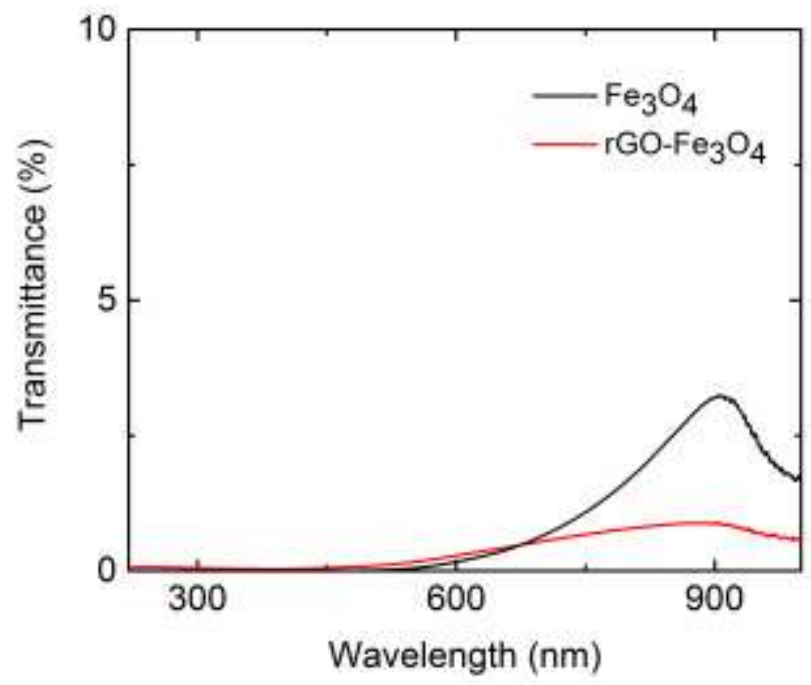

Figure S3. Transmittance of $1 \mathrm{mg} \mathrm{mL}^{-1}$ aqueous dispersions in the wavelength range of 220$1000 \mathrm{~nm}$.

a

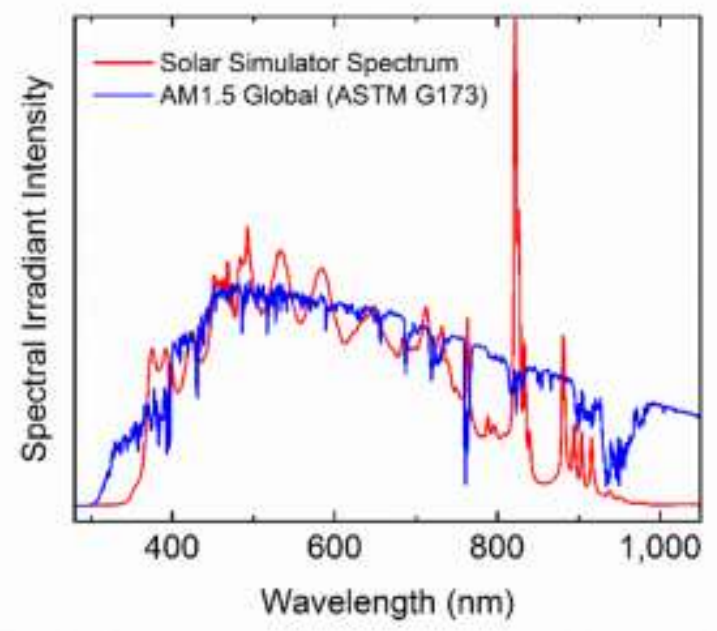

b

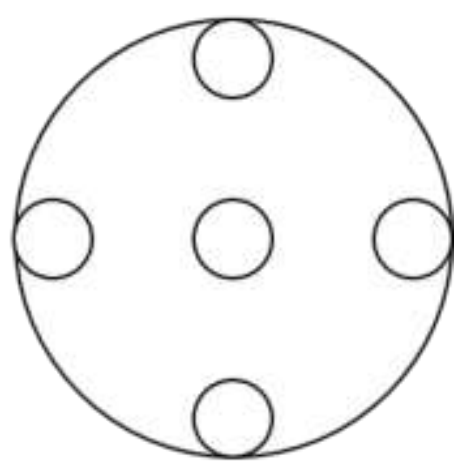

Figure S4. (a) Solar simulator spectrum at $1 \mathrm{~kW} \mathrm{~m}^{-2}$ irradiation compared to the AM1.5 Global spectrum (ASTM G173-03). The strongest characteristic peak of the Xenon lamp appears at $820 \mathrm{~nm}$. (b) 5 typical test points in the area of solution container to measure the power of solar simulator. 
a

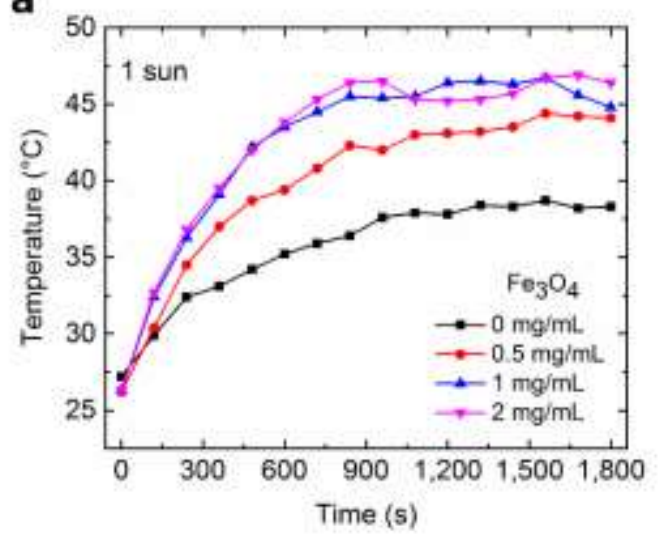

b

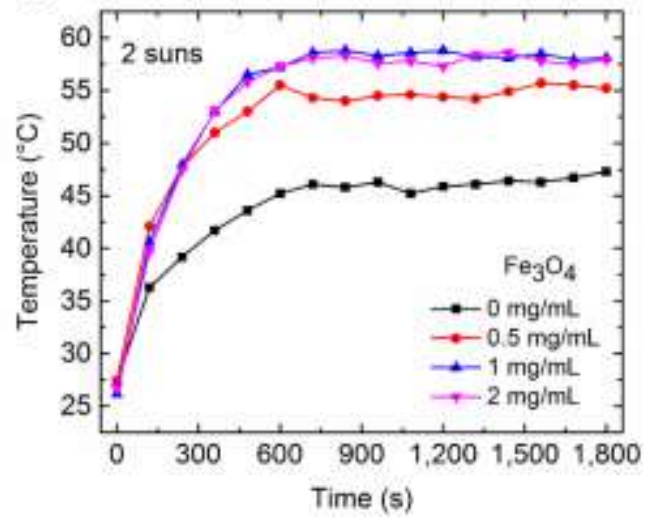

Figure S5. Temperature change for different concentrations of $\mathrm{Fe}_{3} \mathrm{O}_{4} \mathrm{MNPs}$ dispersions under a solar irradiation of (a) 1 and (b) $2 \mathrm{~kW} \mathrm{~m}^{-2}$.

a

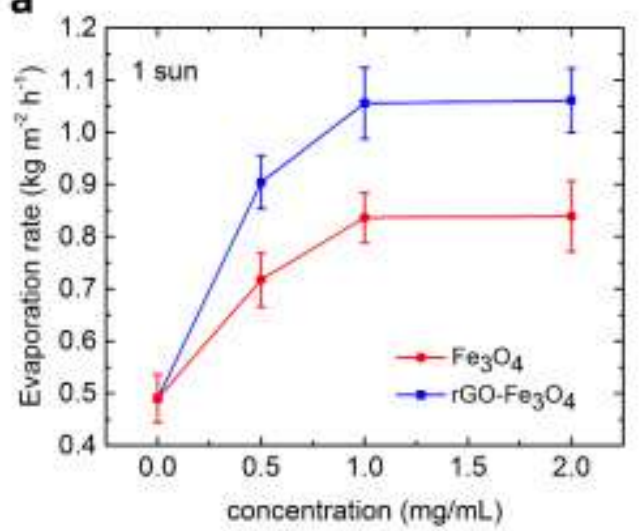

b

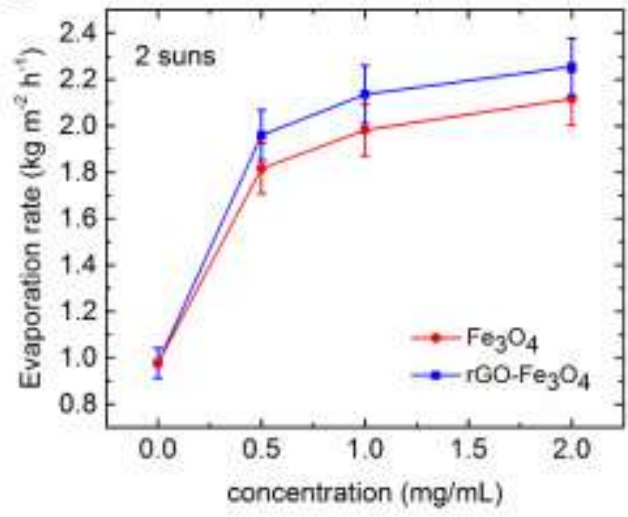

Figure S6. Evaporation rate of different solutions as a function of dispersion concentration under (a) 1 and (b) $2 \mathrm{~kW} \mathrm{~m}^{-2}$ solar irradiation conditions. 


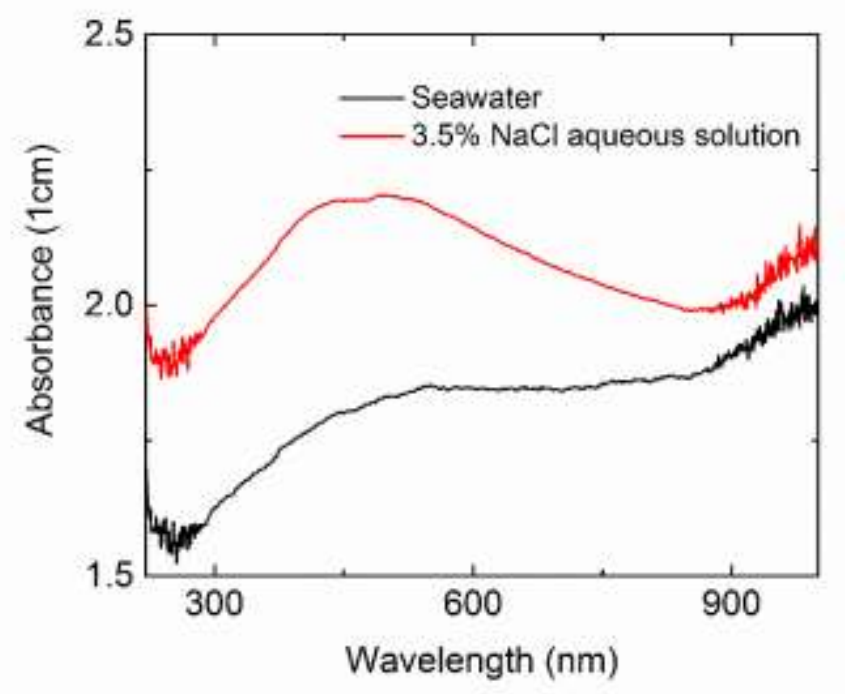

Figure S7. Absorbance spectra of seawater and 3.5\% $\mathrm{NaCl}$ aqueous solution with $\mathrm{rGO}-\mathrm{Fe}_{3} \mathrm{O}_{4}$ dispersed $\left(1 \mathrm{mg} \mathrm{mL}^{-1}\right)$ in the wavelength range of 220-1100 nm.

\section{Note S1. The measure of solar simulator power.}

We use a solar power meter (CEL-NP2000) which has a range of $0-25 \mathrm{~kW} \mathrm{~m}^{-2}$ to measure the power of solar simulator. The range of spectral response is from 190 to $11000 \mathrm{~nm}$ and the response area has a diameter of $1 \mathrm{~cm}$. The diameter of solution container is $5.6 \mathrm{~cm}$. 5 typical points were measured as shown in the Figure S4b, Supporting Information. Under the condition of $1 \mathrm{~kW} \mathrm{~m}^{-2}$ irradiation in this paper, the values are $1.045,0.962,0.957,0.978$, $0.954 \mathrm{~kW} \mathrm{~m}^{-2}$ respectively. Under the condition of $2 \mathrm{~kW} \mathrm{~m}^{-2}$ irradiation in this paper, the values are $2.05,1.90,1.93,1.92,1.94 \mathrm{~kW} \mathrm{~m}^{-2}$ respectively. The standard error is about $\pm 5 \%$. 